\title{
AVALIAC̃̃̃ TÉCNICA E ECONÔMICA DA PRODUC̃̃o DE DUAS CULTIVARES DE ALFACE TIPO CRESPA EM FUNÇÃO DE LÂMINAS DE IRRIGAÇÃO ${ }^{1}$
}

\author{
Technical and economical evaluation of the production of two crisped type lettuce \\ cultivars as a function of irrigation depths
}

\author{
Renato Carvalho Vilas Boas ${ }^{2}$, Jacinto de Assunção Carvalho ${ }^{3}$, Luiz Antônio Augusto Gomes ${ }^{4}$, \\ Alexandre Marcio Gomes de Sousa ${ }^{5}$, Reginaldo Coelho Rodrigues ${ }^{5}$, Kleber Junio de Souza ${ }^{5}$
}

\begin{abstract}
RESUMO
Objetivou-se, com o presente trabalho, a avaliação técnica e econômica da produção de duas cultivares de alface tipo crespa em função de lâminas de irrigação, cultivadas sob ambiente protegido, na região de Lavras, MG. O experimento foi instalado em casa de vegetação, com delineamento em blocos casualizados, em esquema fatorial 2 x 4, com quatro repetições. Os tratamentos constituíramse de duas cultivares de alface, Verônica e Hortência, e quatro lâminas de irrigação, 75, 100, 125 e 150\% de reposição de água, sendo a lâmina de $100 \%$ correspondente à tensão da água no solo de $15 \mathrm{kPa}$. Os resultados permitiram concluir que as duas cultivares apresentaram a mesma tendência com relação ao consumo de água, durante o ciclo de produção (eficiência de uso de água média de $152,27 \mathrm{~kg} \mathrm{ha}^{-1} \mathrm{~mm}^{-1}$ ); maiores produtividades (total e comercial) foram obtidas com a aplicação da lâmina de irrigação de $240 \mathrm{~mm}$ (121,2\% de reposição de água); a máxima produtividade comercial, $33.225 \mathrm{~kg} \mathrm{ha}^{-1}$, foi estimada com a aplicação da lâmina de $244,9 \mathrm{~mm}$ ( $123,7 \%$ de reposição de água); a lâmina economicamente ótima foi estimada em $244,2 \mathrm{~mm}$, resultando em uma produtividade comercial praticamente igual à máxima física.
\end{abstract}

Termos para indexação: Lactuca sativa L., ambiente protegido, irrigação.

\begin{abstract}
The present work had as aim the technical and economical evaluation of the production of two crisped type lettuce cultivars as a function of irrigation depths, cultivated under protected environment in the region of Lavras, MG. The experiment was set up inside greenhouse with randomized block outline in $2 \times 4$ factorial scheme, with four replicates. The treatments consisted of two lettuce cultivars, Verônica and Hortência, and four irrigation depths, 75, 100, 125 and 150\% of water replacement, being the depth of $100 \%$ corresponding the tension of water in the soil of $15 \mathrm{kPa}$. The results enabled to conclude that the two cultivars of lettuce presented the same trend with regard to water consumption throughout production cycle (water use efficiency medium of $152.27 \mathrm{~kg}$ $\mathrm{ha}^{-1} \mathrm{~mm}^{-1}$ ); higher yields (total and commercial) were obtained with the application of the irrigation depth of $240 \mathrm{~mm}(121.2 \% \mathrm{of}$ water replacement); the maximum commercial yield, $33,225 \mathrm{~kg} \mathrm{ha}^{-1}$, was estimated from the application of the depth of $244.9 \mathrm{~mm}$ ( $123.7 \%$ of water replacement); the economical optimum depth was estimated in $244.2 \mathrm{~mm}$, resulting a commercial yield practically equal to the physical maximum.
\end{abstract}

Index terms: Lactuca sativa L., protected environment, irrigation.

(Recebido em 3 de abril de 2006 e aprovado em 23 de abril de 2007)

\section{INTRODUÇÃO}

Em razão da importância do cultivo, em ambiente protegido, para a cultura da alface no Brasil, é de grande interesse o desenvolvimento de pesquisas que subsidiem o aproveitamento do potencial dessa tecnologia nas diferentes regiões climáticas do país, notadamente aqueles necessários ao adequado manejo da irrigação e economicidade do processo produtivo.
Filgueira (2000) relata que a cultura da alface é altamente exigente em água, portanto, as irrigações devem ser freqüentes e abundantes, por causa da ampla área foliar e a evapotranspiração intensiva, bem como ao sistema radicular delicado e superficial e a elevada capacidade de produção. Assim, o mesmo autor descreve que o teor de água útil no solo deve ser mantido acima de $80 \%$, ao longo do ciclo da cultura, inclusive durante a colheita.

\footnotetext{
${ }^{1}$ Parte da Dissertação de Mestrado do primeiro autor apresentada a Universidade Federal de Lavras (UFLA). Trabalho financiado pelo CNPq. ${ }^{2}$ Mestre em Engenharia Agrícola - Departamento de Engenharia/DEG - Universidade Federal de Lavras/UFLA - Cx. P. 3037 - 37200-000 - Lavras, MG renatovilasboas@yahoo.com.br

${ }^{3}$ Doutor em Engenharia Agrícola, Professor Adjunto - Departamento de Engenharia/DEG - Universidade Federal de Lavras/UFLA - Cx. P. 3037 - $37200-000$ Lavras, MG - jacintoc@ufla.br

${ }^{4}$ Doutor em Genética e Melhoramento de Plantas, Professor Adjunto - Departamento de Agricultura/DAG - Universidade Federal de Lavras/UFLA - Cx. P. 3037 - 37200-000 - Lavras, MG - laagomes@ufla.br

${ }^{5}$ Graduados em Engenharia Agrícola - Departamento de Engenharia/DEG - Universidade Federal de Lavras/UFLA - Cx. P. 3037 - $37200-000$ - Lavras,

MG - alexagricola1@yahoo.com.br; regi_coelho@yahoo.com.br; kleber.halwai@bol.com.br
} 
Andrade Júnior et al. (1992), analisando os efeitos de quatro níveis de irrigação baseados na evaporação do tanque Classe A $(0,50 ; 0,75 ; 1,00$ e 1,25), aplicados por microaspersão em alface, constataram que a massa fresca da "cabeça" e a produtividade, apresentaram respostas quadráticas, alcançando os valores máximos de $184 \mathrm{~g}$ e $23.670 \mathrm{~kg} \mathrm{ha}^{-1}$, respectivamente, com o nível de irrigação correspondente a $75 \%$ da ECA.

Estudando os efeitos de quatro níveis de irrigação, baseados na evaporação do tanque Classe A $(0,25 ; 0,50$; 0,75 e 1,00), utilizando irrigação por gotejamento na cultura da alface tipo americana, Andrade Júnior \& Klar (1997) encontraram ajuste quadrático para a produtividade, alcançando o valor máximo de $90.970 \mathrm{~kg} \mathrm{ha}^{-1}$, com o nível de irrigação correspondente a $75 \%$ da ECA.

As funções de resposta das culturas, com bases experimentais, constituem fontes valiosas de informações a serem utilizadas nos modelos de tomada de decisão das empresas agrícolas (FRIZZONE, 1987). Conhecidos os preços dos insumos e dos produtos, pode-se determinar a quantidade ótima de cada insumo a ser utilizado para que a lucratividade do agricultor seja otimizada (PÁDUA, 1998).

Segundo Ferguson (1988), uma função de produção é definida como sendo a relação técnica entre um conjunto específico de fatores envolvidos num processo produtivo qualquer e a produção física possível de se obter, com a tecnologia existente.

Os modelos matemáticos que descrevem uma função de produção mais comumente utilizada nas análises econômicas das pesquisas agrícolas são: Quadrático, Raiz Quadrada, Mitscherlich e o Potência 3/2 (HEXEM \& HEADY, 1978). Entretanto, o modelo polinomial quadrático, utilizado por vários pesquisadores (FRIZZONE, 1987; OLIVEIRA, 1993; PEREIRA, 2005; TARSITANO \& HOFFMANN, 1985), na maioria das vezes, foi o que melhor representou a estimativa de produção, permitindo uma análise que define as doses de máxima eficiência econômica, com o uso da produtividade máxima ou do lucro máximo.

Oliveira (1993) cita que muitos trabalhos de pesquisa, envolvendo irrigação e fertilizantes, apontam recomendações genéricas que objetivam a obtenção de produtividades físicas máximas, sem qualquer preocupação econômica. A utilização da irrigação, com base nessas informações, poderá torná-la inviável do ponto de vista econômico, já que o ótimo econômico, geralmente, não corresponde à máxima produtividade biológica.

Dessa forma, objetivou-se aqui a avaliação técnica e econômica da produção de duas cultivares de alface, tipo crespa, em função de lâminas de irrigação, cultivadas sob ambiente protegido, na região de Lavras, MG.

\section{MATERIAL E MÉTODOS}

O experimento foi conduzido em casa de vegetação, modelo arco, do Departamento de Engenharia da Universidade Federal de Lavras (UFLA), "Setor de Engenharia de Água e Solo", no município de Lavras, sul de Minas Gerais, entre os meses de setembro e novembro de 2005.

O solo foi classificado como um Latossolo Vermelho Distroférrico (EMBRAPA, 1999). Para a determinação da curva característica de água no solo, amostras de solo foram coletadas à profundidade de $0,10 \mathrm{~m}$ e, a seguir, os valores encontrados foram ajustados ao modelo proposto por Genuchten (1980). A tensão de água no solo, equivalente à umidade na capacidade de campo, foi obtida através de teste in loco, conforme Bernardo et al. (2005), tendo o valor de $10 \mathrm{kPa}$.

Foi empregado o delineamento em blocos casualizados (DBC) em esquema fatorial $2 \times 4$, sendo utilizados oito tratamentos e quatro repetições. Os tratamentos constituíram-se de duas cultivares de alface, Verônica e Hortência, e quatro lâminas de irrigação, 75, 100,125 e $150 \%$ de reposição de água. Para monitorar o estado de energia da água no solo, foram utilizados oito tensiômetros, instalados a $0,10 \mathrm{~m}$ de profundidade, nos canteiros com $100 \%$ de reposição de água, para cada cultivar. Para obtenção do momento de irrigar foi utilizada a média dos quatro tensiômetros, sendo que o manejo da irrigação foi realizado separadamente para as cultivares em estudo. A tensão de água no solo, igual a $15 \mathrm{kPa}$ (SANTOS \& PEREIRA, 2004), foi utilizada como referência do momento de irrigar, sendo a lâmina de irrigação de $100 \%$ correspondente a esta tensão. Foram utilizadas quatro linhas de plantas, espaçadas de 0,30 m entre si e 0,20 m entre plantas, totalizando 20 plantas por parcela. Foram consideradas úteis as plantas das linhas centrais, sendo descartadas nessas linhas duas plantas no início e duas no final (parcela útil com 6 plantas).

Utilizou-se de sistema de irrigação por gotejamento, sendo que as linhas de gotejo foram inseridas entre duas linhas de plantio, em cada parcela. A água foi distribuída nos canteiros por meio de tubos de polietileno de diâmetro de $16 \mathrm{~mm}$. Em cada linha dos tratamentos com $100 \%$ de reposição de água havia quatro gotejadores, instalados a $0,25 \mathrm{~m}$ de distância um do outro. Nos tratamentos com 75, 125 e $150 \%$ de reposição de água, havia em cada linha, três, cinco e seis gotejadores, respectivamente. Utilizaramse gotejadores da marca Netafim, modelo P.C.J. com vazão de $2 \mathrm{~L} \mathrm{~h}^{-1}$, trabalhando com uma pressão de serviço de $200 \mathrm{kPa}$. 
O cálculo do tempo de funcionamento do sistema de irrigação foi feito a partir da lâmina bruta calculada de acordo com Cabello (1996), considerando a profundidade efetiva do sistema radicular igual a $0,20 \mathrm{~m}$ e a eficiência de aplicação de água do sistema de irrigação de $90 \%$.

As adubações de plantio e cobertura foram realizadas manualmente com base nas análises de solo e conforme recomendação de Gomes et al. (1999).

Do transplante $(11 / 10 / 2005)$ até o início da diferenciação dos tratamentos (21/10/2005), o fornecimento de água ao solo se deu por meio de um regador manual, uma vez que as raízes se encontravam pouco desenvolvidas, sendo aplicada uma lâmina média diária de 2,67 mm.

Para obtenção da função de produção, utilizou-se a análise de regressão entre a produção comercial e as lâminas de água aplicadas, ajustada por um modelo polinomial de segunda ordem (HEXEM \& HEADY, 1978), sendo:

$$
\mathrm{Y}=\mathrm{f}(\mathrm{W})=\mathrm{a}+\mathrm{b} \cdot \mathrm{W}+\mathrm{c} \cdot \mathrm{W}^{2}
$$

em que,

$\mathrm{Y}=$ produção comercial, $\mathrm{kg} \mathrm{ha}^{-1}$;

$\mathrm{W}=$ lâmina total de água aplicada, $\mathrm{mm}$;

$\mathrm{a}, \mathrm{b}$ e c = parâmetros da equação.

Com a função ajustada, foi determinada a lâmina de água (Wmáx) que maximizou a produção.

$$
\text { Wmáx }=-\frac{b}{2 . c}
$$

A receita líquida ou lucro da produção foi obtido com a diferença entre o valor monetário total da produção e dos custos da aplicação de água e do custo fixo do sistema produtivo, incluindo o sistema de irrigação.

$$
\mathrm{L}(\mathrm{W})=\mathrm{Py} \cdot \mathrm{Y}-\mathrm{Pw} \cdot \mathrm{W}-\mathrm{C}
$$

em que,

$\mathrm{L}(\mathrm{W})=$ lucro, $\mathrm{R} \$$;

$\mathrm{Py}=$ preço do produto, $\mathrm{R} \$ \mathrm{~kg}^{-1}$;

$\mathrm{Pw}=$ preço do fator água, $\mathrm{R} \$ \mathrm{~mm}^{-1}$;

$\mathrm{C}=$ custo dos fatores considerados fixos no experimento.

A maximização do lucro foi obtida calculando-se a derivada de primeira ordem da equação 3 em relação a $W$ e igualando a zero, obtendo-se a equação da lâmina ótima (Wót) que maximizou a receita:

$$
\text { Wót }=\frac{\text { Pw }- \text { Py.b }}{2 \cdot P y \cdot c}
$$

O preço do produto (Py) correspondeu ao preço médio obtido pelo produtor rural, no Estado de Minas Gerais, no mês de janeiro de 2006, que foi de $R \$ 1,00 \mathrm{~kg}^{-1}$ (CEASAMINAS CENTRAIS DE ABASTECIMENTO, 2006).

Para o custo da lâmina de água, em $\mathrm{R} \$ \mathrm{~mm}^{-1}$, foram considerados dados médios do experimento, utilizando-se da metodologia do cálculo do custo da energia para irrigação (CARVALHO et al., 1996).

$\mathrm{O}$ custo de $\mathrm{R} \$ 0,70 \mathrm{~mm}^{-1}$ de água aplicada foi calculado, dividindo-se o custo variável, para 1 hectare, pela lâmina total aplicada ao tratamento, considerando-se $100 \%$ de reposição da água, que serviu como referencial para o reinício das irrigações.

\section{RESULTADOS E DISCUSSÃO}

No período de condução do experimento, as médias de temperatura e umidade relativa do ar no interior da casa de vegetação foram de $25^{\circ} \mathrm{C}$ e $66,5 \%$, respectivamente. Os valores médios de temperatura e umidade relativa estão de acordo com Sganzerla (1995), que relata que a umidade relativa do ar ótima varia de 60 a $80 \%$ e as temperaturas críticas de interferência no desenvolvimento da cultura da alface são abaixo de 10$12^{\circ} \mathrm{C}$ e acima de $30^{\circ} \mathrm{C}$.

Os valores percentuais, inicial e corrigido, de reposição de água ao solo e as lâminas totais de irrigação correspondentes, aplicadas durante a experimentação, encontram-se na Tabela 1.

É importante ressaltar que, as maiores produtividades foram obtidas aplicando-se lâminas de irrigação superiores a $100 \%$ de reposição de água, e possivelmente, isso ocorreu por causa da eficiência global do sistema, ou seja, não houve eficiência de $100 \%$ de absorção de água (há perdas por percolação, redistribuição de água no solo, áreas com déficit hídrico).

Observa-se que a produtividade, tanto total quanto comercial, foi bastante influenciada pelas lâminas de água repostas ao solo (Tabela 2).

No caso das produtividades total e comercial, as variações ocorridas podem ser explicadas pela regressão quadrática (Figura 1), a $5 \%$ de probabilidade.

O ponto máximo para a produtividade total ocorreu com uma lâmina de irrigação de $249,1 \mathrm{~mm}$, resultando em uma produtividade para essa característica de $36.484 \mathrm{~kg}$ $\mathrm{ha}^{-1}$. Já para a produtividade comercial, o ponto máximo foi atingido com a aplicação da lâmina de irrigação de 244,9 $\mathrm{mm}$, resultando em uma produtividade para esse parâmetro de $33.225 \mathrm{~kg} \mathrm{ha}^{-1}$. 
Tabela 1 - Percentuais de reposição de água, inicial e corrigido, e lâminas totais de irrigação correspondentes, aplicadas durante a experimentação.

\begin{tabular}{ccc}
\hline $\begin{array}{c}\text { Percentual inicial de } \\
\text { reposição de água (\%) }\end{array}$ & $\begin{array}{c}\text { Percentual corrigido de } \\
\text { reposição de água (\%) }\end{array}$ & $\begin{array}{c}\text { Lâmina de irrigação } \\
\text { correspondente (mm) }\end{array}$ \\
\hline 75 & 78,3 & 155 \\
100 & 100,0 & 198 \\
125 & 121,2 & 240 \\
150 & 142,9 & 283 \\
\hline
\end{tabular}

Tabela 2 - Resumo das análises de variância e de regressão para a produtividade, total (PT) e comercial (PC), de duas cultivares de alface, sob diferentes lâminas de irrigação.

\begin{tabular}{|c|c|c|c|}
\hline \multirow{2}{*}{ Fontes de variação } & \multirow{2}{*}{ G. L. } & \multicolumn{2}{|c|}{ Q.M. } \\
\hline & & PT $\left(\mathrm{kg} \mathrm{ha}^{-1}\right)$ & $\mathrm{PC}\left(\mathrm{kg} \mathrm{ha}^{-1}\right)$ \\
\hline Bloco & 3 & $89014003,75^{\mathrm{ns}}$ & $66277127,55^{\mathrm{ns}}$ \\
\hline Cultivar & 1 & $12863149,93^{\mathrm{ns}}$ & $3643400,43^{\text {ns }}$ \\
\hline Lâmina & 3 & $180068245,29^{* *}$ & 159259316,70 *** \\
\hline Interação & 3 & $30592833,62^{\mathrm{ns}}$ & $26878444,92^{\mathrm{ns}}$ \\
\hline Resíduo & 21 & 29694773,31 & 23788035,44 \\
\hline Média Geral & - & 32575,25 & 29354,64 \\
\hline C.V. $(\%)$ & - & 16,73 & 16,62 \\
\hline Linear & 1 & $374591940,36^{* *}$ & $296549778,49^{* *}$ \\
\hline Quadrática & 1 & $155564073,69^{*}$ & 171151872,31 * \\
\hline Desvios & 1 & $10048721,82^{\mathrm{ns}}$ & $10076299,32^{\mathrm{ns}}$ \\
\hline Resíduo & 21 & 29694773,31 & 23788035,44 \\
\hline
\end{tabular}

ns - não significativo pelo teste $\mathrm{F}$;

${ }^{*} \mathrm{e}^{* *}$ - significativos a 5 e $1 \%$ de probabilidade pelo teste $\mathrm{F}$, respectivamente.

Os resultados de produtividades, obtidos nesse experimento, estão acima do observado por Echer et al. (2000) que, estudando o efeito do espaçamento de cinco cultivares de alface do tipo crespa (Brisa, Grande Rápida, Marisa, Vera e Verônica AF 257), obtiveram uma produtividade média de $26.950 \mathrm{~kg} \mathrm{ha}^{-1}$, utilizando o espaçamento de $0,25 \mathrm{x}$ $0,25 \mathrm{~m}$.

Esse comportamento é semelhante ao observado por Andrade Júnior \& Klar (1997) que, estudando os efeitos de quatro níveis de irrigação, baseados na evaporação do tanque Classe A $(0,25 ; 0,50 ; 0,75$ e 1,00), utilizando irrigação por gotejamento, na cultura da alface tipo americana, encontraram ajuste quadrático para a produtividade, alcançando o valor máximo de $90.970 \mathrm{~kg} \mathrm{ha}^{-1}$, com o nível de irrigação correspondente a $75 \%$ da ECA.

A partir da função de produção estimada para a produção comercial de alface, foram obtidos os produtos físicos marginais (PFMa), calculados pela Equação 5:

$$
\frac{\partial \mathrm{Y}}{\partial \mathrm{W}}=-2,5244 . \mathrm{W}+618,18=\frac{\mathrm{Pw}}{\mathrm{Py}}
$$

De acordo com a Tabela 3, observa-se que o PFMa é inicialmente positivo e decresce à medida que se aumenta a lâmina de irrigação aplicada ao solo.

Quando o valor do PFMa atinge o valor zero, significa que a lâmina de irrigação aplicada proporcionou a produtividade física máxima. Igualando a primeira derivada a zero $(\mathrm{PFMa}=0)$, a maior produtividade comercial, de $33.225 \mathrm{~kg} \mathrm{ha}^{-1}$, foi obtida com uma lâmina de irrigação de $244,9 \mathrm{~mm}$. A partir do ponto em que o PFMa apresentou valor nulo, a aplicação de maior lâmina de irrigação conduziu ao valor de produto físico marginal negativo, indicando ser não econômico o uso dessa quantidade de água (utilização excessiva de água).

A lâmina de irrigação economicamente ótima foi calculada igualando a expressão do PFMa ao preço do fator variável, obtendo-se, dessa forma, a máxima eficiência econômica. 
Na Figura 2, mostra-se a relação custo/benefício para a cultura da alface, para o mês de janeiro de 2006. Para esse mesmo mês, a lâmina com que se obteve maior lucro foi de 244,2 mm (123,3\% de reposição de água), resultando uma produtividade de $33.224 \mathrm{~kg} \mathrm{ha}^{-1}$.

Observa-se que esse valor de lâmina é bastante próximo do valor da lâmina que gera a produtividade física máxima, o que indica que a irrigação deve ser feita de forma a manter condições ótimas de umidade do solo e garantir o desenvolvimento vegetativo da cultura.

Para atender às diferentes relações entre o preço da água e o preço da alface, construiu-se um gráfico de lâmina de irrigação economicamente ótima $\left(\mathrm{W}^{*}\right)$, em função da relação de preços entre fator e produto (Pw/Py) (Figura 3).

Observa-se que a lâmina total de irrigação economicamente ótima decresce à medida que se aumenta a relação entre preços (Pw/Py). Assim, considerando fixo o preço da alface, verifica-se que, incrementando o preço da água, como por exemplo, realizando o cultivo na zona urbana onde o custo da energia elétrica é superior ao da zona rural e também levando-se em consideração a cobrança pelo uso da água tratada na cidade, a lâmina total de irrigação a aplicar deve ser menor, para que o produtor obtenha o lucro máximo na atividade.

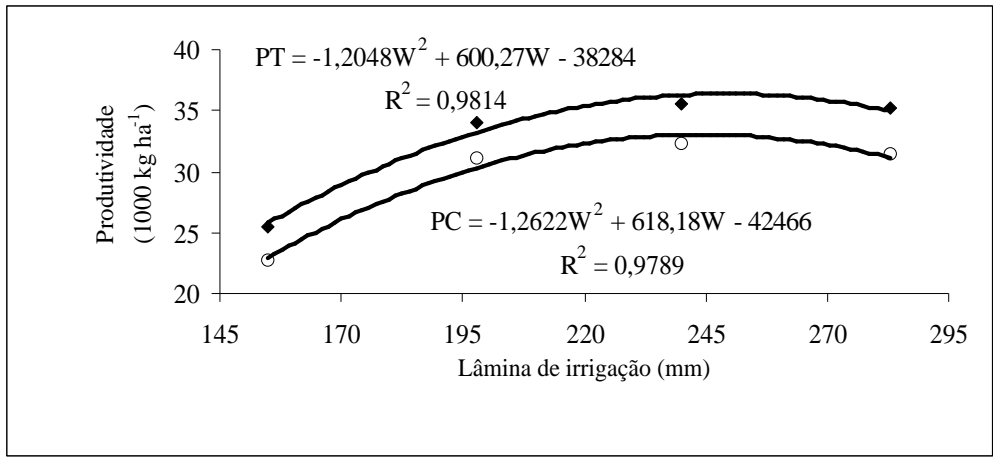

Figura 1 - Produtividade total (PT) e comercial (PC) de plantas de alface, em função das diferentes lâminas de água aplicadas.

Tabela 3 - Produto físico marginal da água (PFMa) para as diferentes lâminas de irrigação aplicadas.

\begin{tabular}{cc}
\hline Lâminas de irrigação aplicadas $(\mathrm{mm})$ & Produto físico marginal da água (PFMa) \\
\hline 155 & 226,9 \\
198 & 118,3 \\
240 & 12,3 \\
283 & $-96,2$ \\
\hline
\end{tabular}

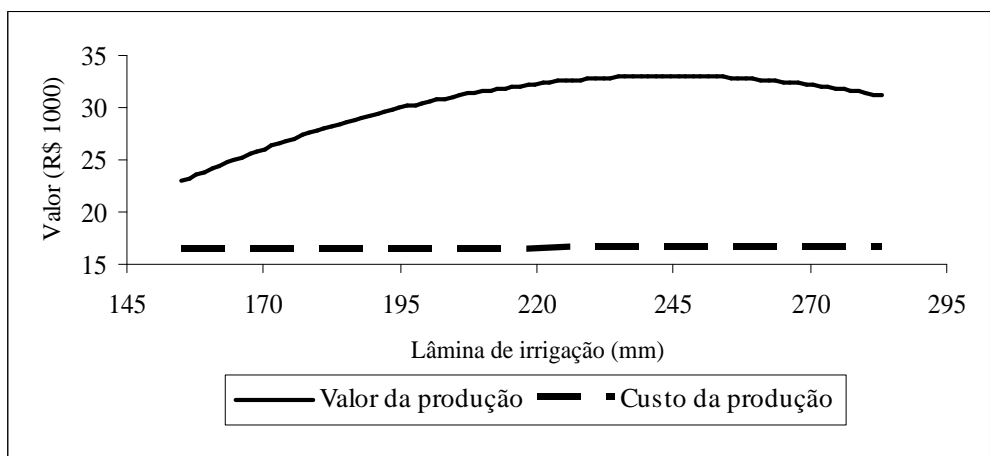

Figura 2 - Relação custo/benefício para a cultura da alface em função da lâmina de irrigação para o mês de janeiro de 2006. 


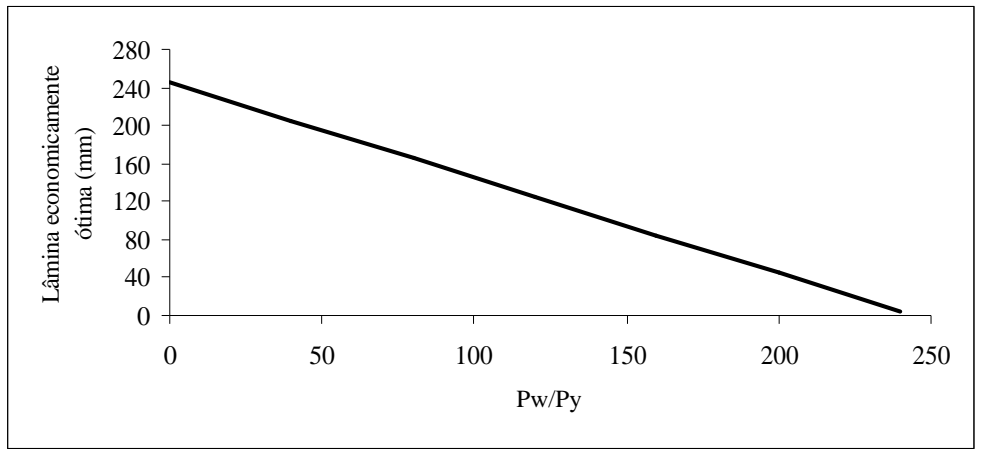

Figura 3 - Lâmina total de irrigação economicamente ótima, em função da relação entre o preço da água e o preço da alface.

\section{CONCLUSÕES}

As cultivares de alface, Verônica e Hortência, apresentaram a mesma tendência com relação ao consumo de água, durante o ciclo de produção (eficiência de uso de água média de $152,27 \mathrm{~kg} \mathrm{ha}^{-1} \mathrm{~mm}^{-1}$ ).

Maiores produtividades, total e comercial, foram obtidas com a aplicação da lâmina de irrigação de $240 \mathrm{~mm}$ (121,2\% de reposição de água).

A máxima produtividade comercial, $33.225 \mathrm{~kg} \mathrm{ha}^{-1}$, foi estimada com a aplicação da lâmina de 244,9 mm (123,7\% de reposição de água).

Considerando o preço da água $\left(\mathrm{R} \$ 0,70 \mathrm{~mm}^{-1}\right)$ e o preço da alface do tipo crespa $\left(\mathrm{R} \$ 1,00 \mathrm{~kg}^{-1}\right)$, a lâmina economicamente ótima foi estimada em $244,2 \mathrm{~mm}$, resultando em uma produtividade comercial praticamente igual à máxima física.

\section{AGRADECIMENTOS}

Ao Conselho Nacional de Pesquisa e Desenvolvimento Científico e Tecnológico - CNPq, pelo auxílio financeiro e ao Departamento de Engenharia da UFLA.

\section{REFERÊNCIAS BIBLIOGRÁFICAS}

ANDRADE JÚNIOR, A. S. de; DUARTE, R. L. R.; RIBEIRO, V. Q. Níveis de irrigação na cultura da alface. Teresina: Embrapa-UEPAE, 1992. 16 p. (Boletim de pesquisa, 13).

ANDRADE JÚNIOR, A. S. de; KLAR, A. E. Manejo da irrigação da cultura da alface (Lactuca sativa L.) através do tanque classe A. Scientia Agricola, Piracicaba, v. 54, n. 1/2, p. 31-38, jan./ago. 1997.

BERNARDO, S.; SOARES, A. A.; MANTOVANI, E. C. Manual de irrigação. 7. ed. atual. e ampl. Viçosa: UFV, 2005. $611 \mathrm{p}$.
CABELLO, F. P. Riegos localizados de alta frecuencia (RLAF) goteo, microaspersión, exudación. 3. ed. Madrid: Mundi-Prensa, 1996. $511 \mathrm{p}$.

CARVALHO, J. de A.; BERNARDO, S.; SOUSA, E. F. Cálculo do custo de energia para irrigação. Campo dos Goytacazes: UENF, 1996. 13 p. (Boletim técnico, 1).

CEASAMINAS CENTRAIS DE ABASTECIMENTO. Boletim diário de preços. Disponível em: <http://www. ceasaminas.com.br/bolgrupo_resp.asp >. Acesso em: 12 jan. 2006.

ECHER, M. de M.; SIGRIST, J. M. M.; GUIMARÃES, V. F.; MINAMI, K. Efeito do espaçamento no comportamento de cinco cultivares de alface. Horticultura Brasileira, Brasília, v. 18, p. 507-508, jul. 2000. Suplemento.

EMPRESA BRASILEIRA DE PESQUISA AGROPECUÁRIA. Centro Nacional de Pesquisa de Solos. Sistema brasileiro de classificação de solos. Rio de Janeiro, 1999. 412 p.

FERGUSON, C. E. Teoria micro-econômica. 11. ed. Rio de Janeiro: Forense Universitária, 1988. 609 p.

FILGUEIRA, F. A. R. Novo manual de olericultura: agrotecnologia moderna na produção e comercialização de hortaliças. Viçosa: UFV, 2000. 402 p.

FRIZZONE, J. A. Funções de resposta do feijoeiro ao uso do nitrogênio e lâmina de irrigação. In: SIMPÓSIO SOBRE O MANEJO DA ÁGUA NA AGRICULTURA, 1987, Campinas. Anais... Campinas: Unicamp, 1987. p. 123-133.

GENUCHTEN, M. T. van. A closed-form equation for predicting the hydraulic conductivity of unsaturated soils. Soil Science Society American Journal, Madison, v. 44, n. 5, p. 892-898, Sept./Oct. 1980. 
GOMES, L. A. A.; SILVA, E. C. da; FAQUIN, V. Recomendações de adubação para cultivos em ambiente protegido. In: RIBEIRO, A. C.; GUIMARÃES, P. T. G.; ALVAREZ, V. H. (Eds.). Recomendações para o uso de corretivos e fertilizantes em Minas Gerais: $5^{\mathrm{a}}$ aproximação. Viçosa: UFV, 1999. p. 99-110.

HEXEM, R. W.; HEADY, E. O. Water production function for irrigated agriculture. Ames: The Iowa State University, 1978. 215 p.

OLIVEIRA, S. L. Funções de resposta do milho doce ao uso de irrigação e nitrogênio. 1993. 91 f. Tese (Doutorado em Irrigação e Drenagem) - Universidade Federal de Viçosa, Viçosa, 1993.

PADUA, T. de S. Espaçamento econômico na cultura do cafeeiro (Coffea arabica L.): um estudo no Sul de Minas Gerais. 1998. 62 p. Dissertação (Mestrado em Economia) Universidade Federal de Lavras, Lavras, 1998.
PEREIRA, J. R. D. Viabilidade técnica e econômica das aplicações de água e nitrogênio no cultivo de gladíolo (Gladiolus $\boldsymbol{x}$ grandiflorus L.). 2005. 80 p. Tese (Doutorado em Irrigação e Drenagem) - Universidade Federal de Lavras, Lavras, 2005.

SANTOS, S. R. dos; PEREIRA, G. M. Comportamento da alface tipo americana sob diferentes tensões de água no solo, em ambiente protegido. Engenharia Agrícola, Jaboticabal, v. 24, n. 3, p. 569-577, set./dez. 2004.

SGANZERLA, E. Nova Agricultura: a fascinante arte de cultivar com os plásticos. 5. ed. Guaíba: Agropecuária, 1995. $342 \mathrm{p}$.

TARSitAnO, M. A. A.; HOFFMAN, R. Análise econômica do emprego de fertilizantes na cultura do milho. Revista Economia Rural, São Paulo, v. 23, n. 3, p. 333349, 1985. 